Urszula Wich-Szymczak ${ }^{1}$

\title{
LIBER PASSUS KLEMENSA STANISŁAWA HERKI - PANEGIRYK Z OKAZJI AWANSU AKADEMICKIEGO. PROBLEMY KOMUNIKACJI LITERACKIEJ POPRZEZ POEZJĘ KUNSZTOWNĄ
}

Klemens Herka ${ }^{2}$ wydał w 1732 r. w Krakowie dziełko Liber passus Apia virtuti eruditae ad secundam laureati honoris metam carmine heroico expeditus com lemmate passum fortuna fecundet ${ }^{3}$. W polskim tłumaczeniu tytuł tegoż zbiorku brzmi: Swobodne przejście (krok) Appijska Droga zastużonej cnoty do drugiej uwieńczonej wawrzynem mety (do drugiego stopnia godności) przedstawione z mottem krokowi (przejściu) niech sprzyja fortuna. Utwór ten to jeden $\mathrm{z}$ wielu ogłoszonych panegiryków Herki. Jest on poświęcony w całości Stanisławowi Wadowskiemu, który uzyskał akademicki stopień doktora.

Postawa panegiryczna ${ }^{4}$ wyraża się wychwalaniem, wywyższaniem człowieka czy wydarzenia w stopniu niewspółmiernym do rzeczywistych cnót, zasług, znaczenia. Autor utworu - pochwały stosował amplifikację, hiperbolę,

1 Katedra Dziennikarstwa i Komunikacji Społecznej Uniwersytetu Łódzkiego.

2 Herka Klemens Stanisław (1713-1759), profesor prawa. W 1729 r. otrzymał w Akademii Krakowskiej stopień bakałarza, w 1731 magistra filozofii. W 1732 r. został seniorem szkoły przy kościele św. Sebastiana w Krakowie. Od 1734 do 1745 r. wykładał na Wydziale Filozoficznym Uniwersytetu Krakowskiego. Uczył też języka francuskiego. W 1745 r. został powołany do Kolegium Mniejszego. W r. 1748 wszedł do kolegium prawniczego. 10 VI 1748 r. mianowano go rektorem Akademii Lubrańskiego w Poznaniu. Stanowisko to zajmował do 1752 r., wykładając jednocześnie prawo kanoniczne i ekonomię teoretyczno-praktyczną. Po powrocie do Krakowa wykładał na Wydziale Prawa kazuistykę, w r. 1758 został prowizorem kolonii w Pinczowie. Wyświęcony został w r. 1736, zajmował szereg stanowisk kościelnych (M. Chamcówna, Herka Klemens Stanisław, [w:] Polski stownik biograficzny, t. 9, Wrocław 1960, s.456457).

3 Cytaty z dzieła K. Herki podaje się za wydaniem: Liber passus Apia virtuti eruditae ad secundam laureati honoris metam Cracoviensi... atrium magister et philosophiae doctor crearetur, directus die vero 2 aprilis [Cracoviae]. Typis Collegii Maioris Universitatis Cracoviensis, Kraków 1732, sygn. BN XVIII.3.3353. Cyfra umieszczona w nawiasie po cytacie oznacza stronicę (karte) tej edycji.

4 Literatura przedmiotu na temat panegiryku jest bogata: H. Dziechcińska, Panegiryk, [w:] Stownik literatury staropolskiej. Średniowiecze-renesans-barok, red. T. Michałowska przy udziale B. Otwinowskiej i E. Sarnowskiej-Temeriusz, Wrocław 1998 (tam podstawowa bibliografia). 
antytezę i inne ,reguły chwalenia”, aby uwznioślana w literackiej laudacji postać była wyniesiona na piedestał, stała się obiektem podziwu, niejako „wzorcem osobowym”. Panegiryk zadomowił się na dobre w poezji okolicznościowej, dotarł do środowiska twórców z kręgu Akademii Krakowskiej ${ }^{5}$. Powstawały tam dziełka chwalące wiedzę, naukę i pracowników nauki. Szczególnie intensywny rozwój twórczości panegirycznej przypada na okres baroku. Właśnie analizowany tutaj zbiorek K. Herki sławiący uzyskanie doktoratu przez St. Wadowskiego to przykład poezji okolicznościowej a zarazem późnobarokowy panegiryk ,akademicki”, o tyle interesujący, że pochwała doktora jest niezwykle kunsztowna, bo wyrażona przy pomocy środków, których dostarcza autorowi laudacji poesis artificiosa.

Po bardzo charakterystycznej dla krakowskich panegirystów akademickich pieśni safickiej (oda saphica) skierowanej do św. Jana Kantego ${ }^{6}$ oraz trzech epigramach ,in stemma... neodoctoris” autor umieścił 230-wersowy poemat heksametryczny Liber passus Appia virtutis emeritae ad secundam leureati honoris metam carmine heroico expanditus cum lemma te. Passum fortuna fecundet. Anon. Po polsku tytuł ten brzmi następująco: Swobodne przejście Appijska Droga zastużonej cnoty do drugiej uwieńczonej wawrzynem mety (tzn. do drugiego stopnia godności akademickiej - U. W-Sz.) pieśnią heroiczną przedstawiona z mottem „Przejściu niech sprzyja fortuna” Anonim. Motto ma tu dodać świetności całej pochwale ${ }^{7}$. Sentencja być może została zredagowana dla potrzeb tego wiersza w oparciu o inne, funkcjonujące w powszechnym obiegu: Fortuna tibi favet (los ci sprzyja); Fortuna favet fortibus (los sprzyja dzielnym). Tutaj łacińskie frazy zostały przekształcone w ten sposób, że zdanie stanowiące motto zawiera życzenie dla nowo wypromowanego doktora, aby jego awansowi akademickiemu dopisywało szczęście (Fortuna), w domyśle znakomita kariera. Wadowski kroczy Appijską Drogą zasłużonej cnoty. Jak wiadomo via Appia to jedna z najstarszych dróg rzymskich (via publica - droga publiczna, państwowa), zbudowana w 312 r. p.n.e. przez Appiusza Klaudiusza Cekusa.

5 Por. E. J. Głębicka, Akademia Krakowska a twórczość panegiryczna w XVII w., [w:] Literatura i instytucje $w$ dawnej Polsce, Warszawa 1994; Zabawy literackie polskich uczonych, zebrał i oprac. H. Markiewicz, Kraków 2007; J. Gruchała, Profesorskie otia (o zainteresowaniach Jana Brożka kulturq popularna), „Ruch Literacki”, R. XXIII, 1982, z. 1-2 (130-131), s. 9-22; P. Rypson, Piramidy, stońca, labirynty. Poezja wizualna w Polsce od XVI do XVIII wieku, Warszawa 2002 (rozdz. 3.1.11).

6 Zob. J. Głębicka, op.cit., s. 53. Badaczka wyjaśnia: ,[...] po beatyfikacji Jana Kantego ustala się zwyczaj poprzedzania odą skierowaną do niego wszystkich wierszy pisanych z okazji uniwersyteckich uroczystości”.

7 Pisał na ten temat H. Markiewicz w pracy: Notatki do historii motta $w$ literaturze polskiej, [w:] Zabawy..., s. 57-70. 
Była uważana za najważniejszą, nazywano ją Regina virarum (królową dróg). Droga Wadowskiego, Via Appia, to najstarsza z dróg intelektualistów, także Regina viarum - droga cnoty, droga mądrości, droga poznania prawd i praw tego świata. Zatem już sam tytuł i motto realizują panegiryczną laudację, uwznioślenie dokonania naukowego nowego doktora.

Poemat dobrze świadczy o akademickim poecie tworzącym okolicznościowe wiersze pochwalne. Utwór jest pełen reminiscencji mitologicznych umieszczonych w tym celu, aby na tle przywołanych realiów dawnej kultury poddać amplifikacji awans naukowy Wadowskiego. Zatem muza epicka Herki nie chce opiewać tych, którzy wstapili w służbę u Marsa, lecz będzie sławić dokonania naukowe doktora Stanisława.

Sed mea Musa canet, quo Stanislaus honores Sumpsit, pro merita, Diva Jagellonis in Aula Pallada et quail percurrit Olympia passu.

Lecz Stanisława zaszczyty pragnie ma Muza wyśpiewać, Które dla zasług otrzymał na świętym dworze Jagiełły I opiewać, jak szybko też pobiegł po bieżni igrzysk Pallady. $\left(\mathrm{k} . \mathrm{B}_{2}\right)$

Jak widać, autor poprzez mitologiczne parantele i nazwanie Akademii Krakowskiej świętym dworem Jagiełły (król ten reaktywował działanie uczelni w 1400 r.) dąży do hiperbolizacji osiągnięć naukowych doktora Wadowskiego, którego właśnie na katedrach osadza Pallada. Bogini mądrości skronie jego pięknego lica opasuje zielenią wieńca laurowego. cnotami:

Wadowski to pod każdym względem vir illustris obdarzony wspaniałymi

Non tu corpus eras sine pectore, Dii Tibi formam,

Dii Tibi mentis opes dederant, animique, vigorem.

Te pietas Divum, Te cultus numinis alti,

Qui miseros reddit mortals rite beatos,

Et sancto teneris, qui robore pectora firmat

Ornabat, Tibi semper errant caelestia curae.

Nil in te reprobum fuerat, quod forte querela,

Aut dignum censore foret, sed sola videri

Excupiit virtus, animo praecelsa profundo,

Et tenera in signis morum constantia fronte.

Te licuid spectare senem iuvenilibus annis,

In cuius vultu, tum mentis amabile pondus,

Tum gravitas micuit, fastu iucunda remoto.

Namque gravi fuerant quae vix praestantda Catoni, 
Tu iuvenis celsa maturus mente gerebat.

Non Tua iucundi mulcebant pectora lusus,

Non recreare Tuam potuere crepundia mentem,

Improba non animum vel mollis inertia vitae.

Nam levibus nunquam voluisti impendere tempus,

Qui semper fueras potius gravioribus aptus.

$$
\text { (k. B }-\mathrm{C})
$$

Nie byłeś ty ciałem bez duszy, kształt piękny ci dali bogowie, Myśli ci dali bogactwo i także ducha moc wielką.

Ciebie miłość do świętych, ciebie cześć Boga na niebie,

Która nieszczęsnych śmiertelnych zwykle do szczęścia prowadzi,

Zdobiła, a ku niebiosom zwracała się zawsze twa troska.

Nic w tobie nie było naganne, by skargi być godnym lub sądu

Lecz tylko cnota być chciała widziana na ducha głębinie

Wyniosłą i obyczajów stałość na młodym obliczu,

Jakby wyryta. Wolno ci było w młodzieńczych już latach

Starca doświadczać. A w twarzy twej ciężar myśli przemiły,

Bądź łagodna powaga błyszczała, z pychy zupełnie wyzuta.

Czego bowiem ledwie dokazać mógł Katon czcigodny

Tyś czynił młodzieniec o myśli dojrzałej, co sięga wysoko.

Nie radowały ci serca zabawy dla innych przyjemne,

Ni kastanietów dźwięki umysłu odświeżyć nie mogły,

Ni ducha bezczynność bezcenna zniewieściałego żywota.

Nigdy bowiem nie chciałeś sprawom miałkim czasu poświęcać,

Któryś był zawsze raczej (bardziej) do rzeczy ważniejszych skłonny.

Panegiryczny wizerunek nowo wypromowanego doktora zawiera również pochwałę genealogiczną. Wiadomo, że Wadowski (1715-1769) pochodził ze szlachty. W latach 1730-1732 studiował w Akademii Krakowskiej, gdzie w 1731 r. uzyskał bakalaureat, a rok później magisterium sztuk wyzwolonych. W Rzymie studiował medycynę, a przed 1749 r. zdobył tytuł doktora. Od roku 1750 był profesorem w Katedrze medycyny teoretycznej i praktycznej na Wydziale Lekarskim Akademii Krakowskiej. Herka głosi laudację przodków uczonego, wyrażając przekonanie, że Stanisław jest godnym spadkobiercą ich cnót.

Natomiast walory intelektualne Wadowskiego zostały opisane przy użyciu amplifikacji. Herka dokonuje uwznioślenia, uszlachetnienia i powiększenia cnót i osiągnięć naukowych, talentów, głębi intelektualnej. Amplifikacji postaci uczonego doktora panegirysta dokonywał przez porównania, wzrost i rozumowanie. Amplifikacja polegała na umiejętnym argumentowaniu ,powiększającym” poprzez porównanie postaci bohatera laudacji (np. pochodzenia) z wielkimi postaciami z historii mitologii grecko-rzymskiej: Pallas-Atena wyłoniła się z głowy Jowisza, Diana była córką Latony itd. Te paralele uwznioślają po- 
chodzenie doktora Stanisława. Herka celowo gromadził i ,zagęszczał” na przestrzeni tekstu liczne dowody świadczące o niezwykłości cnót i talentów doktora Stanisława. W ten sposób bez trudu argumentował, ze Wadowski jest człowiekiem niezwykłym, godnym najwyższych pochwał. W tej konwencji literackiej panegiryczna przesada nie tylko nie razi, ale stanowi sposób skutecznej perswazji. Czytelnik laudacji powinien przyjąć tę hiperbolizację postaci jako dowód, że bohater jest rzeczywiście wielkim człowiekiem. Amplifikacja poprzez nagromadzenie prowadzi do tego, że autor laudacji w sposób skumulowany układał argumenty, dowody na ,wielkość” opiewanego w poemacie uczonego:

In Te deposuit cunctos Pandora decores,
Ingenium Stagyrita suum, Chrysipus acumen,
Cor Pallas, Charites linguam, dedit ora Diones. (k. $\mathrm{C}_{2}$ )

W tobie Pandora złożyła wszystkie wdzięki, Talent swój Stagiryta, umysłu bystrość dał Chryzyp, Pallada znów serce, a język Charyty dał usta Dion.

Herka, autor biegły w sztuce retoryki, umiejętnie stosował amplifikację poprzez rozumowanie, zestawiając takie myśli, argumenty, dowody, które służą wywyższaniu postaci Wadowskiego, wyolbrzymianiu jego zalet, zasług, osiągnięć jako uczonego męża, miłującego sławę, którą uzyskał dzięki wiedzy. Rzeczy wielkich od wielkich ludzi wymaga natura - powiadał panegirysta i drogą rozumowania wskazywał niezwykłość poświęceń uczonego na drodze zdobywania wiedzy.

W zakończeniu panegiryku pojawia się komplement pod adresem „mędrca o myśli wysokiej”, który usilnie i z zapałem wstąpił do świątyni Pallady, gdzie godność doktorska zasiada. Jako zasłużony dla nauki ma wolny wstęp do tego przybytku mądrości. Na zakończenie twórca laudacji zamieszcza kunsztownym stylem wyrażone życzenia pomyślności.

Kolejna część akademickiego panegiryku to popis umiejętności Herki w zakresie poezji kunsztownej. Zawiera on anagramy, obelisk, akrostychy, carmina figurata, wiersz wężowy Sidus virtuti Libero passui praelucens carmen serpentinum. Dzieło wymaga monograficznego opracowania. W krótkim referacie omówione zostaną wybrane formy poezji kunsztownej, w których krakowski profesor głosił laudację nowo wypromowanego doktora.

Odnajdujemy tu wiele wyszukanych form poetyckich, w tym liczne anagramy. Stworzone przez Herkę zabawki poetyckie, należące do nurtu poesis artificiosa, to niezwykle kunsztownie i oryginalnie oddany hołd Wadowskiemu. Ich twórca to poeta ludens. Autorowi udało się opracować kilka bardzo dobrych 
warsztatowo anagramów. Efekt panegiryczny został tu więc również osiagnięty poprzez zastosowanie ciekawych chwytów formalnych, poprzez doskonałość warsztatową i artystyczną, poprzez erudycyjną znajomość cech genologicznych zastosowanych zabawek literackich i poprzez poetycki talent tworzenia tego typu utworków. Jest to konceptystyczna próba uczczenia ważnego wydarzenia przez poetę późnego baroku. Możemy mówić tu o pewnej wirtuozerii warsztatowej autora. W przedstawionych anagramach Herki widać ciekawy i zarazem kunsztowny koncept, lekkość pióra i płynność wywodu.

Oto w zespole utworów, których adresatem jest Stanisław Wadowski, pojawia się cykl anagramów. Każdy z utworów posiada dwie (interesujące nas w tym referacie) części. Pierwsza o charakterze igraszki słownej, druga zaś słowno-metrycznej. Część pierwsza składa się $\mathrm{z}$ nagłówka ${ }^{8}$, zaś z niego (programu) na zasadzie operacji „zmienno literowej” (dotyczy ona oczywiście tekstu łacińskiego) powstają poszczególne wyrażenia opatrzone zbiorczo określeniem anagram z dodaniem cyfry wskazującej kolejność (anagramma I, anagramma II itd.). „Program” składa się z 49 liter. Suma wyrażeń anagramowych jest taka sama.

Na podstawie wyrażeń anagramowych autor komponuje w dystychu eligijnym epigramat. W druku wyrażenia anagramowe wyodrębniono w epigramacie kursywą. Całość obejmuje:

a) nagłówek - program

b) anagramów 6

c) epigramów 6 .

Prześledźmy technikę twórcy wierszy kunsztownych, warsztat panegirysty.

\section{Programma}

M. Stanislaus Vadovius neodoctor, bene et feliciter veniat.

Po polsku:

M. (magister) Stanisław Wadowski (który właśnie uzyskał stopień doktora niech pomyślnie i szczęśliwie przybywa [wzrasta]).

8 Nagłówek, forma wstępna - takie znaczenie przypisuje słowu PROGRAMMA (Stownik grecko-polski, t. 3, pod red. Z. Abramowiczówny, Warszawa 1963, s. 636). 


\section{Anagramma I}

Eia curre, non fileo, novit laus,

Te dotes beatum faciunt sedi.

Po polsku:

Nuże biegnij, nie milczę, wie chwała,

Ciebie zdolności (dary) bogatym czynią siedziby.

\section{Epigramma}

Eia patent aditus liber Tibi passus ubisque

Curre nec ignavas volvito mente moras.

Non fileo quantos sumes a Pallade plausus,

Novit enim virtus, noscet et Orbis eos.

Laus Te tanta manet, nam dotes rite beatum

Te faciunt, sedi vivito doctus huic.

(k. D)

Po polsku:

Nuże wejścia otwarte, wolny dla Ciebie wstęp wszędzie,

Biegnij i nie rozmyślaj w swym duchu o zwłoce leniwej.

Nie (prze)milcze jak wielkie pochwały ma dla Ciebie Pallada,

Wie o nich bowiem cnota, a pozna je także świat cały,

Chwała Cię /tak wielka/ czeka, albowiem zdolności bogatym

Cię czynią bardzo, dla tej tu siedziby żyj jako uczony. (żyj

w służbie nauki, w nauki żyj służbie).

\section{Anagramma II}

Aude, do, Tu mente non vili beas.

Cano Clio, virtus ista se feret.

Po polsku:

Odważ się, daję, ty duchem nie lichym błogosławisz

Śpiewam (ja) Klio, cnota twoja się wzniesie

\section{Epigramma}

Aude Phaebus ait; votis do laurea serta,

Quae Tu non vile mente beas VADOVI.

Has prompsit voces Heliconis Praeses Apollo,

Clio dixit, ego, pectore vota Cano. 
Primus et extremus Te noverit Orbis, et ultra

Humanum virtus se feret ista gradum.

Po polsku:

Odważ się, mówi Feb, daję pragnieniom wieńce z wawrzynów Które Ty błogosławisz nie lichym duchem, Wadowski.

Te wypowiedział słowa Helikonu władca Apollo,

Klio zaś rzekła, ja sercem już to, czego pragniesz, wyśpiewam.

Pierwszy i ostatni krąg Ciebie pozna i ponad

Poziom człowieczy niechybnie twoja wzniesie się cnota.

\section{Anagramma III}

Fiet, vades, en virtus Te vocat, libens dono sola.

Minerva ciet.

Po polsku:

Stanie się, znajdziesz, oto cnota cię wzywa, $\mathrm{Z}$ serca darem sama Minerwa zagrzewa.

\section{Epigramma}

Augur ero fiet, quod vades faustus in altum, Qui modo pro Phaebi germine dexter abis. En virtus Te sola vocat, Tibi curat honores Teque libens dono sola Minerva ciet. Ergo si jam nuc Tibi sic panduntur honores Scandes maiores, ominor, augur ero.

Po polsku:

Wróż będę, stanie się: zajdziesz pomyślnie wysoko Który właśnie odchodzisz szczęśliwy po Feba gałązkę.

Oto cnota Cię sama przyzywa, o twoje zaszczyty Sama Minerwa się troszczy i z serca Ciebie zagrzewa. Jeśli więc teraz już tak otwierają się dla Cię szczyty Większe jeszcze osiągniesz, przeczuwam, niemylny wróż będę. 


\section{Anagramma IV}

Te ait, noto, mel dulci fundis ab ore, vovens, eas et vincas iter.

Po polsku:

(przez) Cię przemawia, znanym,

miód lejesz z ust słodkich, życząc, byś szedł i przezwyciężał, drogą (ę)

\section{Epigramma}

Dum Te Pallas ait noto STANISLAE WADOWSKI,

Mel video dulci fundis ab ore loquens.

Ergo mella loquens Cathedram conscende decoram,

Hoc Tibi, devincto suadeo corde vovens

Prosper eas meritis et vincas dura laborum,

Istud serta Tibi laurea pandet iter.

$$
\text { (k. } \left.\mathrm{D}_{1}\right)
$$

Po polsku:

Pallas gdy przez Cię przemawia boś znanym jej o Stanisławie Wadowski, miód, widzę, ty lejesz z ust swoich słodkich.

$\mathrm{Z}$ wymowy więc swojej słodyczą wstąp na katedrę wspaniałą.

To Tobie sercem oddanym doradzam, $\dot{z} y c z q c$ zarazem

Abyś pomyślnie szedt ku zasługom i przezwyciężat

Trudów mozoły. Ta droga do wieńców z wawrzynu prowadzi.

(lub: trudów mozoły. Wieniec z wawrzynu tę drogę $\mathrm{Ci}$ jawi)

\section{Anagramma $V$}

Nate novo contu en virtis Tibi facit

De se meliores laudes.

Po polsku:

Zrodzony nowym wysiłkiem, oto cnota Tobie czyni z siebie lepsze pochwały

\section{Epigramma}

Nate novo Cathedris conatu Palladis Almae,

Nobilis en virtus plaudit honore Tibi,

Atque facit de se meliores omine fausto

Laudes, dans meritum pulchra corona decus. 
Ergo Palladiae magnum decus esto coronae,

Virutisque Tuae sit comes omnis honor.

(k. $\left.\mathrm{D}_{1}\right)$

Po polsku:

Nowym zrodzony dla Katedr wysiłkiem łaskawej Pallady

Oto cnota szlachetna zaszczytnym Cię darzy poklaskiem

Oraz czyni z siebie lepszq niż znak pomyślny

Pochwate piękny wieniec dając, należną ozdobę.

Palladyjskiego ozdobą wieńca bądź zatem wielką

Cnocie też twojej zaszczyt wszelaki niech towarzyszy

\section{Anagramma VI}

Io stans laus, i cieo, e te doce, in mundi

Fortuna laurus te beet.

Po polsku:

Hej, stojąc sława, idźże dalejże, co wiesz, głoś,

W sąsiednie strony, (Oby) szczęściem wawrzynu cię obdarzył

\section{Epigramma}

Io Musa canas stans laus ascendit honores,

I toto, cieo, fama vel Orbe vola;

E te cuncta doce, nunc in consinia mundi

Fer plausus, nam post Roma Quirina sciet.

Haec Te Doctorem iam fert, ego pectore vota,

Fortuna laurus Te beet omnis honor.

(k. $\left.\mathrm{D}_{1}\right)$

Po polsku:

Hej, Muzo, śpiewaj ty stoją, sława niech się pnie ku zaszczytom Idźże ty, wieści, przez świat cały albo go obleć, dalejże

Co wiesz, głoś wszędzie; teraz pochwały w sąsiednie nieś strony Bo przecież potem pozna je także Rzym Kwirynowy

Ta Cię już głosi doktorem, ja w sercu niosę życzenia

Oby Cię szczęściem obdarzyt wawrzynu zaszczyt wszelaki

Jak można było zauważyć hasłem anagramu w każdym z przedstawionych utworów jest sentencja zawarta w Programie, informująca o tym, że grono znakomitych intelektualistów właśnie się powiększyło, gdyż dołączył do niego 
Stanisław Wadowski. Ciekawym zabiegiem formalnym jest to, iż w zasadzie Herka tworzy anagram dwukrotnie: najpierw z Programu poszczególne anagramy (sześć utworów), a następnie wykorzystuje ich treść, tworząc epigramaty. Poprzez zastosowanie kursywy poeta po raz kolejny przekształca hasło. Jest to dość rzadko spotykany zabieg, gdyż często wiersze ,pod anagramem” jedynie komentowały jego treść, a sporadycznie zawierały w sobie poszczególne słowa.

Anagramy pełnią ważną rolę w komunikacji literackiej. Mianowicie stanowią bardzo oryginalną formę wytwarzania, przekształcania i przekazywania informacji pomiędzy autorem i czytelnikiem. „Zmiennoliter” wymaga aktywnej postawy odbiorcy tekstu, jego wysiłku intelektualnego, aby mógł właściwie odebrać komunikat autora, wymaga też znajomosci „szyfru”, za pomocą którego wiadomość zostaje przekazana. „Komunikacja to nie dawanie lecz prezentacja samego siebie, swojego życia, która ewoluuje odpowiednie procesy życiowe w kimś innym", . Bardzo istotne są relacje między nadawcą i zakładanym przez niego odbiorcą dzieła, odbiorca interpretującym je. Poesis artificiosa wymaga posiadania przez jej twórcę i przez czytelnika tej samej wiedzy o jej cechach gatunkowych, zdolnościach, osobliwościach komunikacyjnych, uatrakcyjniających i wzmacniających proces przekazywania informacji, nawiązanie przez nich specyficznego dialogu. Jest to działanie komunikacyjne uwarunkowane kulturowo:

Dialog ten wyznacza charakterystyczną jednokierunkowość - złożony typ kontaktu komunikacyjnego jest tutaj dziełem tylko jednego uczestnika, tzn. nadawcy. By odbiorca stał się partnerem uczestniczącym w komunikacyjnym procesie odbioru i rozumienia tekstu, nadawca musi wcześniej - na podstawie różnorakich przesłanek tekstowych - owego odbiorcę tekstu zaprojektować, a nawet wykreować ${ }^{10}$.

Innym gatunkiem poezji kunsztownym wykorzystanym przez Herkę do celów panegirycznych jest akrostych - również $w$ oświeceniu jedna $\mathrm{z}$ ulubionych form zabawy literackiej. Akrostychy występują w trzeciej części Liber passus. W partiach poprzedzających ją znajdujemy ciekawe anagramy i epigramaty. Interesująca nas pod względem akrostychu część trzecia utworu otrzymała od twórcy graficzną formę obelisku ${ }^{11}$, a poeta tak ją tytułuje:

\section{Libero passui \\ Initialis Obeliscus}

${ }^{9}$ M. Fleischer, Podstawy konstruktywistycznej i systemowej teorii komunikacji, [w:] Język w komunikacji, t. 1, red. G. Habrajska, Łódź 2001, s. 86.

${ }^{10} \mathrm{D}$. Ostaszewska, Interakcje komunikacyjne $w$ tekście artystycznym. Na wybranym materiale wspótczesnej prozy, [w:] Interakcyjny wymiar dyskursu artystycznego, red. B. Witosz, Język artystyczny, t. 13, Katowice 2007, s. 12.

11 Por. P. Rypson, op. cit., s. 116-118. 
Cum Lemmate

Plus ultra

(k. $\left.\mathrm{D}_{2}\right)$

$\mathrm{W}$ polskim tłumaczeniu:

Dla swobodnego przejścia

Obelisk poczatkowy

$\mathrm{Z}$ napisem (tytułem)

JESZCZE DALEJ

Po tytule objawia się oczom czytelnika sam obelisk. Wygląda on następująco:

Adonims.

Pberes: $\rightarrow$ a tus fcandis honore

Pindar: $>$ Ima bonum Tibi Pallas ome

Glicors. Zjofcens te mericis ben

Arcbilocb: $n$ ndicat ad fua ferta rocand

Aleman: is olers nam magc, noverat illa, qui

Arat Dim: Tacurus eras mente, Lyce

Pbalescig 2 udux miuteris ad decus proinde to

Aleaicm $₹$ irture grandi quod Tibi competi

Afclepia. co candene alea gradús tramite libier Saphicm \& nicus nec re comirecur ofo Scazon D t ipla virtue Te trahat bono duet

lamb: $O$ ans liberum passum labor Spondai: O mné Te magno monltrat decoratũ cule Pentam. $\longleftarrow$ ade precor velox, Certaǵs carpe vi Hexa: $-\mid$ nfero non filtes ulera plus ire licebi

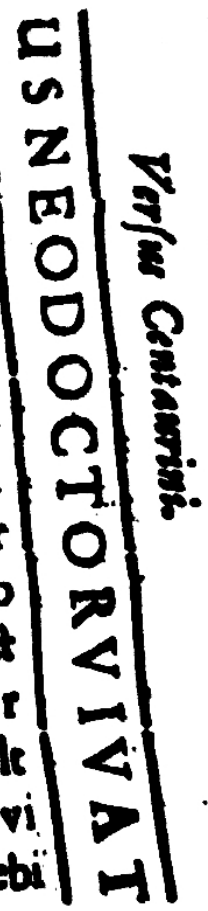

$\left(\mathrm{k} . \mathrm{D}_{2}\right)$

Lewy blok obelisku tworzy zdanie akrostychiczne bez podziału wyrazowego STANISLAUS VADOVI, z prawej strony odnajdujemy telestych - US 
NEODOCTOR VIVAT. W tłumaczeniu polskim oznacza to: STANISŁAW WADOWSKI NEODOCTOR NIECH ŻYJE. Wyrazy te, których kolejne litery (jak to w tego typu utworach) są inicjalnymi i finalnymi literami kolejnych części tekstu (wersów) zajmującego środkową część obelisku. Każdy z odczytanych w ten sposób wersów otrzymuje na zewnątrz obelisku (od lewej strony) określenie swej miary metrycznej. Wszystkie wersy en bloc, a jest ich 16 (jednostek jest 15, ponieważ versus spondaicus, to tylko pewna forma heksametru daktylicznego) otrzymują z prawej strony obelisku określenie zbiorcze: Versus Centaurini - wiersze centaurowe, centauryny. Obelisk ze swoim bogactwem form metrycznych dowodzi świetnej znajomości prozodii i wersyfikacji starożytnej: tym bardziej rzuca się w oczy błąd iloczasowy w pierwszej stopie ostatniego wersu, który zamiast daktyla ma postać kretyku (-v-). Nie jest to wyraz rzadki, a przeciwnie, częstotliwość jego występowania w łacinie po prostu uniemożliwia przyjęcie przypuszczenia pomyłki autora; stąd koniektura: infra w miejsce infero.

Pod obeliskiem autor umieścił napis, a konkretnie dystych elegijny, o następującej treści:

En Obeliscus adest pete, cur non sisto colossum?

Virtuti gradus hic terminus esse nequit.

(k. $\left.\mathrm{D}_{2}\right)$

W polskim thumaczeniu oznacza to:

Oto obelisk przed nami. Dlaczego nie stawiam Kolosa?

Cnocie? Bo stopień ten końcem nie może być.

W dziele Herki odnajdujemy jeszcze jeden utwór akrostyczny. Jest on warsztatowo dość skomplikowany. Oprócz tradycyjnego akrostychu, mamy również mezostych oraz telestych. Wszystkie te utworzone są ze słowa STANISLAUS. A oto omawiany utwór: 
Svpremi quibus Entheus eft in pectore vate $\mathbf{S}$ Vos Voco, vos culco præconia ludite $V_{\text {ers }} \mathbf{V}$ A urDegArciceners Tu frirps Latoni $A$ magn $A$ $L_{\text {ude Ly }}$ â, magnas laudes HeLiconiePrefuL Sublimesá; Sorent Cæli fub Sidera plaufuS Ingeminent $I_{0}$ c elf $i$ is $I_{n}$ collibus Ham $\mathrm{Nunc}_{\text {cantent pxa }} \mathrm{N}$ mufx, nunc Nobile $\operatorname{carmc} \mathbf{N}$ A ufpicijs AltisdüDoctoralif $\quad r$ e r $\mathbf{A}$ Tramice vircutum $\boldsymbol{T}_{\text {endes }} \mathbf{T}$ oleransá; c apeff $\mathbf{T}$ S tanislavs, eum virtus A pientia dotes Torrens eloquij $T_{\text {ongoris }} T_{\text {orquè decoran }} \mathbf{T}$ A liô qux folendent $\mathbf{A}_{\text {nimô Cxlefti }} \mathbf{A}$ d o $\mathbf{n}$ A Nufcitur ingenio $\mathrm{N}_{\text {avas bene }} \mathrm{N}_{\text {afcitur ome }} \mathbf{N}$ Integer Infigni virtus Iungetur honorI Scprecor,haS conor de pectore $S_{\text {pargere voce }}$ Laus Tus $L_{u f t r a}$ ferat, cafus fit LubricgexuL A fir $A$ benigna Tibi faveant, \& tempora $A$ long $A$ $\mathrm{Ve}$ Veniant, fis continuo profperrimus $\mathrm{V}$ s $\mathrm{S}$ is fofpes, tribuant fortes Tibi fata recundź $\mathbf{S}$ 
Utwór składa się z 19 wersów. Prawy bok to akrostych, który tworzą litery czytane od 10 wersu do góry (dają one podane wcześniej rozwiązanie Stanislaus), ten sam wyraz odnajdujemy, czytając od wersu 10 w dół. Mezostych tworzą również litery składające się na imię Wadowskiego. Punktem kluczowym w tym wariancie jest litera $\mathrm{S}$ po środku utworu, $\mathrm{z}$ której to „wypływa” imię STANISLAUS ku prawej i lewej górze (czytając wspak) oraz ku prawemu i lewemu dołu, czytając utwór normalnie. Znajdujemy również z prawej strony wiersza telestych, którego rozwiązanie jest identyczne, z tym pojawiającym się po stronie przeciwnej wiersza, czyli od 10 wersu czytając wspak (STANISLAUS) oraz od $10 \mathrm{w}$ dół (to samo hasło).

Jak wiadomo panegiryk ma być zwierciadłem cnót postaci, której jest poświęcony. Jest narzędziem do tworzenia idealnego obrazu osoby chwalonej. Herka sięgnął po najbardziej doskonały pod względem warsztatowym sposób sławienia Wadowskiego, mianowicie po poezję kunsztowną, opartą na koncepcie, na pięknie gry słownej, na ciekawym ujęciu wizualnym. Wykorzystując te środki artystyczne, a także cechy genologiczne gatunków poezji poesis artificiosai, poeta stworzył panegiryk o bardzo wysokich walorach artystycznych. W poemaciku tym autor wyraźnie zawarł cele dydaktyczne, zaś samemu przekazywaniu wzorców towarzyszy adulatio - pochlebstwo. Mamy tu również amplifikację cech i działań bohatera pochwały, zaś sama laudacja ma charakter egzemplaryczny i pouczający (gdzie znowu przejawia się dydaktyczny charakter gatunku). Dobór środków artystycznych przez Klemesa Herkę nie był przypadkowy. Wspomniana poesis artificiosa to doskonały środek, a właściwie narzędzie kreowania wzorca osobowego bohatera, dające autorowi wiele swobody artystycznej w doborze najodpowiedniejszych środków.

Należy również zwrócić uwagę na aspekt komunikacyjny tego wyrafinowanego panegiryku. Poezja kunsztowna już sama w sobie - w swych założeniach genologicznych - jest nastawiona na bliski kontakt z odbiorca. Jej zadaniem jest zaskoczyć, zadziwić, wciągnąć w grę intelektualną, sprawdzić rzutkość umysłu czytelnika, ale także dostarczyć mu wysokich doznań estetycznych. Gatunki poezji kunsztownej użyte przez Klemensa Herkę do wychwalania Stanisława Wadowskiego to głównie anagram i akrostych. Charakteryzują się one dialogowością, otwarciem na czytelnika. Jest to poniekąd wymuszone - istnieją one ,realnie” tylko wtedy, gdy odbiorca odnajdzie klucz do ich interpretacji. Cechą panegiryku, a w zasadzie założeniem jego twórcy jest to, żeby utwór dotarł do jak największej liczby odbiorców i pozostał w ich pamięci jak najdłużej. Gatunki poesis artificiosa dawały mu nie tylko taką możliwość, ale i tego gwarancję. Ciekawy konceptystyczny utwór zagadka, w którym wymagało się od odbiorcy czynnego, aktywnego zaan- 
gażowania intelektualnego, nie mógł szybko ulecieć z pamięci, z głowy. Przeżycia i doznania duchowe po takiej potyczce, grze pozostawały na długo. Należy zwrócić uwagę również na to, że Herka sięgnął po dość nietypową formę panegiryku. Zamiast „,normalnej” amplifikacji opartej na przesadnych chwaleniu zaprezentował uwznioślenie postaci przyjaciela przy zastosowaniu narzędzi, jakich dostarczała poezja kunsztowna. Była to szlachetna forma uwznioślania postaci w panegiryku, gdyż chwaliło się bohatera utworu za realne osiągnięcia, w sposób wyrafinowany pod względem warsztatowym, bez poniżania się autora utworu laudacyjnego. 